\title{
MOĞOLCADA PEKİŞTİRME VE YANSIMA / ÜNLEM SÖZLER
}

Tuncer GÜLENSOY*

\begin{abstract}
Özet
Moğolca, Türkçe ile yakınlığı birçok bilim adamı tarafından farklı platformlarda tartışılmış olan bir dildir. Dolayısıyla iki dil arasında karşılaştırmalar yapılarak iki dilin yakınlığg ile ilgili farklı görüşler ileri sürülmüştür.

Bu çalışmada Moğolca ile Türkçe arasındaki ilişki temelinde iki dilin ortak yönlerinden biri olan pekiştirme ve yansıma / ünlem sözler üzerinde durulacak ve iki dilin birbirine yakınlığına katkı sunulacaktır.
\end{abstract}

Anahtar Kelimeler: Türkçe, Moğolca, Pekiştirme, Yansıma Sözler.

\section{EMPHASIS, ONOMATOPOEIA/EXCLAMATION WORDS IN MONGOLIAN}

\begin{abstract}
Mongolian is a language whose affinity with Turkish has been argued in different platforms by many scientists. So different opinions have been submitted about their relation by comparing them.

İn this study, emphasis, onomatopoeia/exclamation words which are common features of both languages will be dwelled on within basis of Turkish and Mongolian relation and contribution will be provided to their affinity.
\end{abstract}

Key Words: Turkish, Mongolian, Emphasis, Onomatopoeia.

Türkçenin kelime hazinesi "zengin", cümle yapısı diğer dillere göre "kolay”, ekleri, sıfatları, zarfları, yansımaları (onomatope), zamirleri, pekiştirmeleri ve gramer sözlüklerinde yer alan öteki konularının tanımlanması oldukça kolaydır. Türkçe öyle zor öğrenilen bir dil değildir. Nasıl yazılıyorsa, genellikle öyle okunan bir dil olduğu için en kolay öğrenilebilen bir "dünya dili"dir. İngilizcedeki gibi "ONE" yazılıp "VAN" okunan ve "BİR" anlamına gelen karmaşık bir yapıs1 da yoktur.

Bu araştırmamızda, pek çok Türkoloğun ihmal ettiği bir bilim dalından örnekler vererek o dilin Türkçeye ne kadar yakın olduğunu vurgulamaya çalışacağım. Şimdiye kadar yaptığım araştırmaların 1şı̆̆ında Moğolca ile Türkçenin akrabalığını, bu akrabalığın yalnız söz(cük) alışverişi (alıntı/verinti) olmadığını belirtmeye çalıştım. Bu konuda yazdığım pek çok makale ile kongre/sempozyumlara sunduğum tebliğlerimin dikkatle okunması sonucunda konu daha iyi anlaşılacaktır. Batılı ve Türkiyeli bazı Türkologlar "Türkçe-Moğolca akrabalı̆̆ı"na inanmadıkları için "ırk akrabalı̆̆ı"nı da öne sürmekte, Moğollar (ve Mançu-Tunguzlar, Japonlar ile Koreliler) "sarl ırk", Türkler ise "beyaz ırk"tır diyerek "dil akrabalı̆ğ"n1 reddetmektedirler. Bu reddetme bu kadarla kalmamakta, Mayalar, Inkalar, Keçualar ve Amerid diller adını verdikleri (Apaçi/Apache, Mohikan'lar, Seminol'ler, Navaho'lar, Kutchin'ler, Dene'ler \{=Athapaskan'lar\}, Na-Dene'ler vb. gibi) Kızılderili ile bazı Afrika dillerinin akrabalığına inanmakta, Türkolojinin çalışma sahasını daha da genişleterek genç araştırıcıları zora sokmaktadırlar. Onların unuttukları bir gerçek ise bembeyaz (=appacık)

* Prof. Dr., Emekli Öğretim Üyesi, el-mek: t.gulensoy@ gmail.com

(D) ORCID ID: https://orcid.org/0000-0002-3052-2518 
Norveçliler, İsveçlililer, Almanlar, İngilizler, Danlar ile kapkara (=simsiyah) Farslar ve Hintlilerin akrabalıklarıdır. İşe deri rengi de girince ne diyecekler, ben de merak ediyorum! Farsça der, peder, mâder, birâder; İngilizce door, father, mother, brother sözcükleri birbirlerine benziyor diye renklerini görmemezlikten mi geleceğiz. [one/yek, two/dü, three/se, four/cahar, five/penç, six/şeş sayıları benzemiyormuş ama olsun mu! diyeceğiz..]

Türkolojinin kaynakları eski yazılı eserler (yazıtlar, yazmalar vb.), ağız araştırmaları, sözlükler gibi el altı malzemeleridir. Türkçenin kelime hazinesinin zenginliğini, halk edebiyatını ve bilimini anlatan Dîvânu Lugâti't-Türk gibi ilk sözlügümüzden bu yana pek çok sözlük araştırmalarımıza ve eserlerimizi yazmaya kaynaklık yapmıştır. Ama ne yazık ki Moğolcanın söz hazinesi ile ilgili o kadar çok sözlüğe sahip değiliz. Kowalevski, F. Boberg, F. D. Lessing gibi sözlükçülerin eserleri de pek çok Türkoloğun kütüphanesinde yoktur. Değerli Türkolog arkadaşım Prof. Dr. Günay Karaağaç'ın Ferdinand D. Lessing' in İngilizce eserinden tercüme

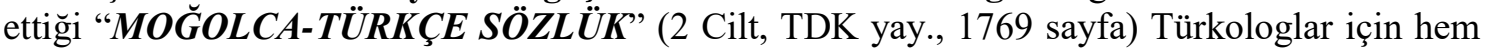
dil hazinesi hem de gramer bilgileri için çok zengin malzemeler içermektedir. Türkçe $=$ Moğolca akrabalığı yanında sözcük benzerliklerinin zenginliği Türkologlar için önem arz etmektedir.

Daha önce hazırlayıp yayınladığımız "Moğolların Gizli Tarihindeki Türkçe Kelimeler Üzerine Bir Deneme" (1973), "Eski ve Orta Türkçede Moğolca Kelimeler ve Moğolca Türkçe Müşterek Kelimeler Üzerine Notlar" (1974), "Eski Türk ve Moğol Şahıs Adlarının Cumhuriyet Dönemindeki Görünümü" (1981/tebliğ), "Eski Türk ve Moğol Şahts Adlart Üzerine" (1982), "Mongolian Loan-Words in Anatolian Dialects" (1988/teliğ), "Altaistic, Mongolistic and Anatolian Dialects" (1997/tebliğ, 2000); "Börteçine ve Temüçin" (2000), "Moğolca ve Türkçede Yaşayan Benzer Sözler" (2011), ve daha başka tebliğ ve makalelerimden sonra hazırladığım "Türkçe mi?, Moğolca mı?" adlı karşılaştırmalı araştırmam pek çok Türkoloğu bu konuda çalışmaya yönlendirecek niteliktedir.

\section{Moğolcada Pekiştirme Sözler}

Aşağıdaki Moğolca "pekiştirme" örnekleri Türkçedeki örneklerine birebir benzemektedir. Türkçedeki [apak, apal, aparı, apaynı, apaz, appacık, bembeyaz, bombok, bombol, büsbütün, çırçıplak, çırllçıplak, dımdızlak, dipdiri, dosdoğru, dümdüz, epeğri, gepgenç, gepgeniş, gömgök, güpgüzel, hıphızlı, ipiyi, kapkara, kaskatı, kıpkızıl, kipkirli, kopkolay, kupkuru, masmavi, mosmor, sapasağlam, sapsarı, semsert, semsessiz, sepserin, sepsessiz, sımsıcak, sımsıkı, sipsivri, şimşişman, şipşirin, tastamam, tertemiz, tostoparlak, yap(a)yalnız, yemyeşil, yopyoğun, yusyuvarlak, zopzor.] gibi pekiştirmelerin kullanılışı Moğolcadaki gibidir. Bunların arasında bazı anlam farkı olanlar çıkabilirse de geneldeki benzerlik ilgi çekicidir.

\section{Moğolca pekiştirme örnekleri:}

ab / av /: "a-" hecesi ile başlayan belirli slfat ve zarflardan önce kullanılan pekişstirici ilk hece tekrart: ab adali : "tastamam, tamamen benzer veya aynı"; ab arigun "aparl, tertemiz"

cab / zav / : "ca-" hecesi ile başlayan: cab calaguu "gepgenç, pek genç"

cub / zuv / : "cu-" hecesi ile başlayan: cub cucagan "yopyoğun, çok kalın, pek yoğun"

cüb /züv / : "cü-" hecesi ile başlayan: cüb cüger-e "tam tamına, tam böyle"; cüb cüger-e sagahu "hiçbir şey yapmamak; aylak ve başıoş olmak"

çib / çiv / : "çi-" hecesi ile başlayan : çib çike "dosdoğru, tamamen doğru"; çib çimeğe ügey "semsessiz, sepsessiz".

çöb / ŝöv / : "çö-” hecesi ile başlayan: çöb çögeken : “apaz, çok küçük, çok az”

deb : "de-" hecesi ile başlayan: deb değer-e "oldukça yüksek, en tepede"; deb demey "tamamen gereksiz, yararsiz" 
gab / gav / : "ga-" hecesi ile başlayan: gab gagca "yalnız, yapayalnız, tek, biricik, tek başına"; gab gagçagar "yalnızca, tek başına"

geb / gev / : "ge-" hecesi ile başlayan: geb gegegen "çok parlak, çok açık"; geb genedte "ansızın, birdenbire, beklenmedik şekilde"; geb genedteken "ansızın, birden-bire"

hab /hav / : "ha-" hecesi ile başlayan: hab halagun "sımsıcak, çok sıcak"; hab har-a "kapkara"; hab harangguy "kapkara, çok karanlık"; hab hatagu "kaskatı, semsert, taş gibi sert"

hub /huv / : "hu-" veya "hagu-" heceleri ile başlayan: hub haguray "kupkuru, tamamen kuru"; hub hurdun "hıphızlı, çok hızlı"

ib / iv / : "i-" hecesi ile başlayan: ib ile "apaçık, açık"; ib ilerkey "apaçıkça, açıkça"; ib icil "apaynı, tam olarak aynı"

keb / hev / : "ke-" hecesi ile başlayan: keb kedüken "apaz, az, pek az, sadece birkaç"

köb / höv /: "kö-" hecesi ile başlayan: köb köke "gömgök, yemyeşil, masmavi”; köb könggen "kopkolay, pek hafif, pek kolay"

küb / hüv / : "kü-" hecesi ile başlayan: küb kündü "çok ağır” çok değişik"

ob /ov / : "o-" hecesi ile başlayan: ob oyrhan "yapyakın, pek yakın"; ob ondu "apayrı,

öb / öv / : "ö-" hecesi ile başlayan: öb örgen "gepgeniş, oldukça geniş, enli”

sab /Sav / : " sa-" hecesi ile başlayan: sab sayhan "ipiyi, pek iyi, çok hoş"; sab sayi "tam bir dakika önce, az önce"; sab sanagan-du ügey "beklenmedik bir şekilde, umulmadık bir şekilde"

seb / sev / : "se-" hecesi ile başlayan: seb sem-iyer ahu "sepsessiz durmak, sessiz durmak, sessizliği korumak"; seb serigün "sepserin, çok serin" çok sarı"

sib / şiv / : "si-" hecesi ile başlayan: sib şineken "yepyeni, çok yeni”; sib şir-a "sapsarl,

şab / şav / : "şa-" hecesi il başlayan: şab şaldang "çırçıplak, çırılçıplak"

tab / tav / : "ta-" hecesi ile başlayan: tab targun "şimşişman, çok şişman"

teb / tev / : "te-" hecesi ile başlayan: teb tegsi “dümdüz, tamamen düz, eşit, benzer"; teb teneg "tam aptal, çok budala"

töb / töv /: “tö-” hecesi ile başlayan:töb tögürig "tamamen yuvarlak, yusyuvarlak"

ub / uv / : "u-" hecesi ie başlayan: ub ulagan "apal, kıpkırmızl, tamamen kırmızı”; ub ulaym-a temür " kıpkırmızı kızgın demir"

üb / üv /: "ü̈-" hecesi ile başlayan: üb ünen "dosdoğru, ek doğru"

Görüldüğü gibi bir sözlük içinde yer alan örneklerden başkaları Moğol ağızlarında ya da öteki Moğol dillerinde yaşamaktadır. Yapılacak tek şey genç ve yetenekli Türkologların Moğolcayı öğrenmeleri, Türkçe ile karşılaştırmalı araştırmalar yaparak ortaya yeni malzemeler koymalarıdır.

\section{Moğolcada Yansıma / Ünlem Sözler}

abau : Korku veya öfke ünlemi: Ay, of, ah, abov!

age : Kağanların veya soyluların oğullarına seslenirken kullandıkları saygı sözü (esk.)

agi : Başka bir kimsenin oğlundan söz ederken kullanılan yüceltici söz. 
ahay : Evli bir kadına hitap etmek için kullanılan saygı sözü (esk.)

anir: Gürültü, ses; yankı; söylenti; dedikodu.

anirla- : seslenmek, ses çıarmak, gürültü yapmak; yankılamak.

ay : Acıma, sempati, endişe, korku ifade eden ünlem: ah!, ay!

bübey : Ninni, bebeği avutma sözü.

cirgire- : Cırlamak, hırlamak, zırlamak, homurdanmak, hırıldamak; çınlamak, vizildamak, c1vıldamak. [cir 'yansıma' + KIrA-]

cirgir-e : Cırcır böceği, Ağustos böceği. [cir 'yansıma' + KIrA > +gir-e $]$

cirkira- : Hıçkırmak, inlemek, sızlamak. [cir 'yansıma' + KIrA]

çer çer kikü : Cırcır etmek, cıvıldamak, çatırdamak.

ebey = ebebeü, ebeü, ebü̈̈ /eviy / : Ah! eyvah! yazık! (acıma, pişmanlık veya şefkat bildirici ünlem.)

esi / eş / : Acıma, memnuniyetsizlik veya küçük görme ifade eden ünlem edat.

ey / iy / : Ey! (Şefkat, keder, korku veya tiksinti bildirir ünlem.)

hag (yans.) : hak, balgam veya tükürme sesi. krş. Tü. hak tu!

haha [= ha ha] $\ddot{U} n l .:$ ha-ha!; haha kiki : ha-ha-ha!

har kir / har har (yans.): gacir gucur, sürtme.

har sir (yans.) : haşır huşur, yere sürülen ayak sesi.

hard (yans.) : hart hurt, diş gicırdatma, kırma veya köpek ısırma sesi.

hohuy /hohoy / (ünl.) : Oh, eyvah, yazık!; hohuy alag : Eyvah, yazık!

kerd (yans.): Kurt, kesme sesi, kirt kirt.

keüre- / hüreh /:Gevremek, kırılmak, koparılmak, gevrek olmak.

keüreg / hüreg /: Çatırtılı, gevrek, kırılgan, nazik; yumuşak.

kürkire- / hürhreh / (yans.): Gurlamak, homurdamak, hırlamak, (şelale) gürlemek;

nohay kürkirekü “(köpek) havlamak” [ kür 'yansıma'+KIrA-]

orkira- /orhiroh / : kükremek, kişnemek, bağırmak, homurdanmak; 1slık çalmak. [or 'yansıma' $+\boldsymbol{K I r} \boldsymbol{A}$-]

ser / ser / : Rüzgârın sesi; ser ser salkilahu "rüzgâr hışırdıyor."

tas tas : çatırtı sesi.

tas tes : kırılan odun sesi.

tüs (yans.): tıs tıs, kıp kıp, birden ortaya çıkan ses, kıpırtı.

tüs tas: tıs tıs, kıpır kıpır, tos tos (sesi).

uli- /ulih / : ulumak, (kurt, köpek vb.) inlemek.

uray : 'Yaşa, hurra!' diye bağırmak. [ < Tü. ur-un ha!]

Görüldüğü üzere Türkçedeki yansıma ve ünlemler Moğolcadaki örneklerinden fazla ve daha zengindir. Bu konuda "Moğolların Gizli Tarihi" ve "Altan Topçi" gibi Moğolca eserler üzerinde yapılacak bilimsel araştırmalar ile daha zengin malzeme elde edilerek hem tarihî hem de modern Moğolcanın dil malzemesi zenginleşecektir. 


\section{Kaynaklar}

BURAN, A. - YILDIRIM, N. (2018). Doğumunun 80. Yllında Prof. Dr. Tuncer Gülensoy, Uluslararası Türk Lehçe Araştırmaları Dergisi (TÜRKLAD), Cilt 2, Sayı 1, s. 1-62.

GÜLENSOY, T., (1973). Mongolistik Üzerine Türkiye'de Yapılan Yayınlarla İlgili Bir Bibliyografya Denemesi. Bibliyografya-Kitap Haberleri Bülteni KHB, C.II /3 (May1s 1973), s.72-76.

GÜLENSOY, T., (1974). Eski Türk ve Moğol Askerlik Teşkilâtının Benzeyen Taraflarıyla Çinggiz Khan'ın Büyük Yasası'ndaki Askerî Cezalar. Töre, S. 24, s. 11-15.

GÜLENSOY, T., (2000). Altayistic, Mongolistic and Anatolian Dialects. Hasan Eren Armağanı, Ankara: TDK Yayınları, s.190-195. 196-199.

GÜlENSOY, T., (2000). Börteçine ve Temuçin. Hasan Eren Armağanı, Ankara: s.

GÜLENSOY, T., (2008). Altan Topçi. Ankara: Kültür Ajans Yayınları.

GÜLENSOY, T., (2009). Ötemiş Hacı Cengizname. Ankara. Kültür Ajans Yayınları.

GÜlENSOY, T., (2009). Ötemiş Hacı Cengizname. Ankara: Kültür Ajans Yayınları.

GÜlEnSOY, T., (2013). Türkçe ile Moğolca İlişkileri. Prof. Dr. Leyla Karahan Armağanı, Ankara: Akçağ Yayınları, s. 515-532.

GÜLENSOY, T., (2017). Altayistik-Mongolistik-Halk Bilimi Makaleler-2. Ankara: Akçağ Yayınları.

GÜLENSOY, T.-Küçüker, P., (2015). Eski Türk-Moğol Kişi Adları Sözlüğü. İstanbul: Bilge Kültür Sanat Yayınları.

İPEK, B. (2018). Tuncer Gülensoy'un Altayistik ve Moğol Halkbilimi Çalışmaları, Uluslararası Türk Lehçe Araştırmaları Dergisi (TÜRKLAD), Cilt 2, Sayı 1, s. 69-81.

KAYA, M. L., (2017). Moğolların Gizli Tarihçesi (Moğolların Kırmızı Kitabı). İstanbul: Kabalc1 Yayınları, 2011, Kronik Yayınları.

LESSING, F. D. (2003). Moğolca Türkçe Sözlük. (çev., Günay KARAAĞAÇ), Ankara: TDK Yayınları. 